Names, Vol. 38, No. 4 (December 1990)

\title{
The Many Faces of Nicknames
}

\section{Theodore J. Holland, Jr.}

\begin{abstract}
Despite a vast scholarly literature on general naming practices, the serious investigation of nicknaming has barely begun. Pertinent literature lies thinly and sporadically scattered throughout the journals of social science disciplines, with most studies of nicknames assuming a structural, functional, psychodynamic, or socio-historical perspective. Taken as a whole, this body of literature is suggestive of the true dimensions of nicknaming.
\end{abstract}

$* * * * *$

Despite a vast scholarly literature on naming and terminology, nicknaming itself has received astoundingly little serious research attention. James K. Skipper, Jr., writing in 1984, briefly reviews a mere seven research studies and then states that "this about exhausts our scholarly knowledge of American personal names." He proceeds to state that "the leading onomastic journal Names has published only two articles on the subject [i.e., American nicknames] in over a quarter century of its existence" ("Sociological Significance" 29). To these could be added a number of studies of nicknaming practices in other cultures, and a few general statements in the popular press.

While scholarly interest in nicknaming practices has been relatively sustained over the past two decades (as opposed to a condition of utter neglect!), having increased significantly since the 1960s, it is nonetheless quite apparent that serious investigation of nicknames has barely begun. It is still the case that "there has been little research on their meaning, significance, and use by members of any discipline" (Skipper, "Nicknames, Folk Heroes and Jazz Musicians" 52). Despite the availability of volumes such as dictionaries of pseudonyms and nicknames, studies of East-Anglian nicknames (Seltén) or Middle English nicknames (Jönsjö), etc., only a single volume can be put forward as examining the social consequences and functions of nicknames (Morgan et al.). For the serious researcher, the virtual sum total of nicknaming literature lies sporadically scattered throughout the scholarly journals of social science disciplines.

Irrespective of the relative dearth of available information on nicknaming, the researcher who presumes to study nicknames is nonetheless 
not without guidelines. The available literature, scant though it be, is richly suggestive of the many functions and roles which nicknames can assume or fulfill. A chronology of the studies which have investigated nicknaming would serve little purpose other than to project to the reader the fragmentary nature of that collective endeavor; rather, this essay will briefly touch upon the various perspectives and functions and roles for nicknames which have emerged out of those studies, and which seem to weave a common strand throughout that widely and thinly scattered literature. It is in this manner that we can best gain an understanding of the multiplex nature of this common phenomenon.

Nicknames are used in different ways by different groups of people, and it is not possible to understand the depth of their interface with their respective societies without studying the demographic and social structures, the cultural milieu, out of which their usage arises.

Many studies indicate the utility of nicknaming as an identifying or classificatory mechanism in cultures where ambiguity exists in the formal naming system. Joseph G. Fucilla, in examining the use of Portuguese nicknames as surnames, observes that "foremost among the reasons for their existence has been the need ... to distinguish between different members of a family unit, often between those bearing the same first and the same family names" ("Portugese" 74). He notes a similar role in his inspection of Spanish nicknames being utilized as surnames. Maurice A. Mook, in studying the Amish, finds that most given names derive from the Bible, and therefore it is not uncommon that individuals within a community share the same names. States Mook (111): "In such communities nicknaming runs rife, almost as an onomastic necessity. ..." The Amish thus derive nicknames from first names, first name plus middle initial, physical or personality traits, events in one's life, or from one's occupation or geographic location. Christopher S. Hale, in studying Icelandic personal bynames, likewise found nicknames used as unofficial designations which characterized individuals by features such as physical or personality traits, occupation, origin, events, or habits. This was particularly important as virtually no family names were used in medieval or early modern Scandinavia; as Hale states: "Undoubtedly the main reason for their popularity was that they offered a ready means of distinguishing people with the same first name from each other" (397).

Nicknames also serve, in Richard Breen's study of naming practices in Western Ireland, to distinguish households where there is much formal duplication of names. A man's nickname would often apply to his 
entire household and could derive from such attributes as physical or personality traits, occupation, or lineage. Such nicknames have been relatively short-lived, and this probably indicates that they were used "to set up relationships of difference-to distinguish-between current households" (708). This is important where there are many surnames and forenames, and nicknames here thus serve a somewhat different classificatory function than, say, on Tory Island (Ireland), where their greater emphasis on similarity and retention of patronyms and matronyms validates one's genealogical position in a social matrix where inheritance and claims to property are dependant upon that position (Breen; Fox).

Indications of the classificatory or identity functions of nicknames also arise in a number of other literatures. Nicknames function to reduce ambiguity of reference in Zinacantan, Mexico, where individuals are identified as to lineage segments by nicknames - often based on surnames, occupation, geographical location, appearance, or behavior which serve to subdivide most lineages (Collier and Bricker). Richard A. Barrett, studying nicknaming practices in Northern Spain, states that "they serve as a shorthand means of identifying every member of the community" (106); Stanley H. Brandes reports from Navanogal, Spain, that "as in most Spanish communities of its size and general character, people may be known more by their nickname ... than their surname" ("Structural" 140); and David Gilmore similarly notes that community nicknaming in Spain can serve to provide identification where more formal cognomens overlap.

Writing about an Arab village, Richard T. Antoun likewise reports that "nicknames have structural significance, distinguishing both individuals and groups," and that nicknames "avoid confusion by identifying individuals immediately and unambiguously" (159-60). Nicknames in the British West Indies are one manner of expressing individuality where extended families mean many shared surnames (Manning). S. D. Goitein and Ray L. Cleveland, studying the tenth through thirteenth century Geniza documents, note that Arabic nicknames frequently assumed usage as family names; and Nancy Dorian reports from the Scottish Highlands that "the high incidence of identical names ... leads to the use of 'by-names' almost to the exclusion of official names" (303). Myrdene Anderson reports the identity functions of nicknames among the Saami of Norway, Sweden, and Finland; while David W. Maurer and Allan W. Futrell investigate the use of "monickers" to provide identification among criminals while preserving the 
secrecy of one's real name. Nicknames in prison settings are often painfully appropriate, and focusing as they often do on some special event in the inmate's life or on his method of operation or criminal specialty, serve not only to maintain identity, but also to compel the bearer to live up to the implications inherent in the name (Maurer and Futrell; Bruce Jackson). Concealment of identity also arises as one obvious reason for the adoption of a nickname or pseudonym in Walter L. Wakefield's examination of medieval French inquisitorial documents.

While nicknames thus undoubtedly serve as mechanisms of classification and identification, these are by no means their only roles. Indeed, nicknames rarely if ever serve a singular function, but instead simultaneously play a variety of roles within the social environments in which they occur.

Nicknames, for example, can function as instruments of social solidarity. As Skipper notes in his 1986 study of coal miners and their nicknames: "groups which face an external threat to the group itself, or to individual members, and which can best maintain the existence of the group and the safety of its members through a cooperative effort, are likely to have a high degree of solidarity" (137). Nicknames help construct and are symbols of such solidarity. Skipper found that their use was common practice in coal mines, serving as the badge of a miner's acceptance and membership in the work group - a mechanism of integration which contributed to both production and safety in the mines.

In Dorian's study of nicknaming in the Scottish Highlands, the high incidence of identical names leads to the use of nicknames as mechanisms of identity as discussed previously. The actual use of such names, however, demands social competence in order to evaluate the offensiveness of such names - a knowledge of social structure which is available only to "insiders." The use of nicknames, especially offensive ones, takes on social significance in that their covert usage can occur only in the company of like-minded people. "Consequently," states Dorian, "one way in which a group of friends express social solidarity is in freely using certain offensive by-names among themselves" (313).

Functions of social solidarity likewise arise in nickname usage among the Saramaka Maroons of Surinam (Price and Price). The use of nicknames, being as they are intimately linked to the bearer, is usually avoided as an important aspect of good manners. The use of such names requires a certain level of friendship or relationship if intimacy and etiquette are not to be violated, thus conferring "an opportunity for the 
strengthening of chosen social ties" (351). M. Aziz F. Yassin, studying personal address among the Kuwaiti Arabic, similarly notes the use of nicknames between close friends. Such names, often based upon an individual's behavior or other personal attributes, imply a friendship more intimate than that shown by personal names. John H. McGeachy, in studying student nicknames for college faculty, notes that nicknames can "serve to integrate the community" (282).

George M. Foster, in investigating the speech forms and perception of social distance in Tzintzuntzan, a Mexican village, states that good friends were generally known by nicknames, whose cautious use denoted intimacy. Such names could, however, also convey enmity and "pecking order," and served not to counter or moderate a particular relationship, but to "accentuate the relationship as it is perceived to be: more intimacy if intimate, enmity or contempt if distant" (119). Nicknames can thus serve to maintain the character of social relationships as they are experienced by community members.

Brandes, in studying the structural and demographic implications of nicknaming in a Spanish village, likewise illustrates, in two articles, the operation of nicknames in the ratification of social ties. In Navanogal, little social stratification is evident, and the nuclear family constitutes the basis of village organization. The nuclear family does not accommodate all needs, and though villagers distrust those with whom they must affiliate, emotional and material security nonetheless demands that social ties be extended into the community via friendship and neighborship. Friendship emerges as the only significant voluntary bond in village society, and though "fraught with suspicion ... it is considered ... worthy of protection." As Brandes states, "By making nickname address acceptable only to friends men can temporarily overcome the anxieties inherent in their relationship and thereby ratify their special tie" ("Structural" 142). The use of nicknames thus correlates with friendship as an expression of that voluntary tie; and nickname reference provides a feeling of trust and cohesion among villagers. Implied therein is yet another function that nicknames can perform - that of boundary maintaining mechanisms (such as between friend and nonfriend); and Brandes hypothesizes that a certain demographic threshold is necessary in order to support the mechanics of internal differentiation which his study implies.

Eugene N. Cohen, in studying nicknaming among the inhabitants of Collefiore, an Italian village, provides an example of boundary maintenance. His interpretation derives from "within the context of village 
socio-centrism, that powerful sense of local pride and patriotism which in Italy is termed campanilismo" (106). Nicknames - commonly derived from physical or behavioral attributes, roles or occupations-require a knowledge of situationally correct usage which only an insider to a particular community can possess. Their use thus implies "an understanding and acute comprehension of the complicated and shifting set of social relations that link the village population together" (109). It is that comprehension which provides an assertion of differences between villages; nicknames thus foster a sense of community discreteness, and operate, as Cohen states, "as boundary-defining and boundary-maintaining mechanisms for groups to whom separateness, difference, and distinctiveness are of particular value and importance" (103).

Often concomitant with any or all of the functions thus far mentioned is the endowment of nicknames with powers of social control. Abraham Iszaevich, in studying naming systems in Catalonia, Spain, briefly mentions that nicknames reinforce the social bonds between those who use them, and "may be used to exercise social control" (324), essentially by reducing social distance and defining villagers as equals.

Antoun, in his previously mentioned study of names in an Arab Muslim village, states that a majority of nicknames reflect an aspect of personality, and do not convey so much the content of a particular norm as "the degree of dissatisfaction provoked by its violation." Nicknames thus "reflect the susceptibility of all villagers to social control," and their character of abusive equality "defines each man as a member of the community and, hence, subject to its norms" (166). Nicknames reflect the intimate knowledge which villagers possess of each other, an awareness which frequently finds utility in settling disputes; likewise, the ethical condemnation inherent in such names is readily apparent, as for example in their frequent orientation toward backbiting and slander - a behavior soundly deplored by Islam.

Numerous other studies also touch upon the roles which nicknames can play as agents of social control, a few examples being those by Brandes ("Structural"), Rom Harré, Theodore J. Holland, Jr. ("Nicknaming Practices"), John H. McDowell, Morgan et al., and Julian A. Pitt-Rivers. In thus defining social boundaries or acting as mechanisms of social control, the powerful capability of nicknames to serve as educators as to the appropriate norms of social conduct and behavior becomes apparent.

In addition to elucidating the major and minor functions of nicknames 
in various cultures, available literature sometimes provocatively hints at the complex and systemic nature of the interrelationships among those varying functions and their social environments. Taken collectively, the literature of nicknaming practices in the child's world constitutes such an example, including the studies by Gary Alan Fine, Harré, Ron Harris, Allison James, Morgan et al., Iona and Peter Opie, Nicholas Tucker, and Henry Van Buren.

Morgan et al. sum up the literature of nicknaming in the child's world, giving a fascinating account rich in conjecture and anecdote though somewhat lacking in analytical rigor. They show children's nicknames to originate either from internal formulation (based upon a feature of the language itself, such as rhyming with a given name), or from external formulation (taking as its referents such extralinguistic variables as physical, behavioral, or intellectual qualities, memorable events, traditions, or cultural stereotypes.

Nicknames in the child's world can serve to create and maintain social classes and mark off the boundaries of friendships and well-knit groups, defining and strengthening animosity toward outcasts and the unpopular. As Morgan et al. state: “... there is a close relation of the social structure of the class to its nicknaming system ...; nicknames can actively mark out groups or individuals and indeed are often consciously used for this purpose" (63). They also, by focusing on such attributes as physique, intelligence, or race, promulgate the valued norms of their social milieu: "nicknames highlight deviations from normality and, as a corollary, indicate the accepted aspects of that society" (69). Social dominance arises as a factor in such nicknaming, with the norms established and enforced generally being those of the dominant group within the subculture; the frequency of categories of nickname referents therefore reflect that dominant clique's perception of the relative importance of those norms.

In addition to delineating groups and promulgating prevalent norms, nicknaming in the child's world can also confer status, validate one's claim to attention, guide one's preconceptions of others, mask one's identity from outsiders, and serve as a mechanism by which a child can render more manageable those who have power over him. Frank Kehl, in "Chinese Nicknaming," recognizes a similar function, as does McGeachy, in "Nicknames for College Faculty," who labels it "compensation." A sensitive appraisal of nicknaming practices can therefore afford great insight into the world view and social dynamics of the group contexts in which they arise. 
Studies of Chinese nicknaming practices reveal a diversity of sociological functions. Nicknaming is extremely common throughout Chinese culture and frequently derives from physical appearance, personality, and habit, as well as from references to animals, literature, or other associations. They can serve not only to label an individual or express one's dislikes toward another person, but also as mechanisms to uphold cultural ideals or even to acquire prestige, especially for those who are clever at creating nicknames. They also function powerfully to define inappropriate or excessive behavior. Kehl states: "Critical nicknames can run the whole gamut of group behavioral norms, nothing seems to be excluded from driving in the stakes of acceptable limits" (160), the nicknamed person serving as a negative model to others.

Chinese nicknames often promote in-group solidarity. As Wolfram Eberhard notes, "nicknames always seem to refer to members of a certain social group ..." (218), and the nickname-creating group is bound together by the names and secrets of which it alone is cognizant. We thus get a picture of a nicknaming in-group "as being privy to secrets, privileged in its use of nicknames for its own members, and unified in terms of its consensually validated perceptions of outsiders" (Kehl 164).

Nicknames also reflect other aspects of Chinese culture, examples being the Chinese language's high degree of homonymy which surfaces in the enhanced potential of nicknames for verbal play ard punning (such as through tonal change), and the reduced level of reference to social roles and self-expression on the part of women's nicknames - which mirrors their status and position in that society (Eberhard; Watson).

As an addition to the structural and functional themes which form the basis of many of the investigations thus far reviewed, Gilmore brings a psychodynamic interpretation to his study of community nicknaming in Spain. In this Mediterranean cultural milieu, which features strong concepts of masculine respect and individual identity and autonomy, an atmosphere of rivalry coexists with an awareness of dependence within the community. Nicknames provide a form of ridicule and repressed antagonism, a displacement of competitive envy which allows one to gain dominance over others in the competition for reputation. They thus represent a weakening of individual autonomy in a context where interdependent people compete for resources. As Gilmore states, "When people experience deeply ambivalent feelings about neighbors, provocative nicknames are used not only as a displacement for conflicted hostile feelings, but also to damage rivals..., to gain dominance over others 
..., [and] to achieve a symbolic mastery ..." (698). Nicknames arise as agents of ego-identity and oral aggression.

Our understanding of nicknaming practices is similarly augmented by several studies which view nicknames not as elements of static systems but as components of dynamic ones, reflections of changes occurring within a society. Barrett's study of changing nicknaming practices in Northern Spain provides such an example.

In the Spanish town of Fuenmayor, modernization and the influx of metropolitan culture is leading to a fragmentation of community networks and an erosion of the convivial and gregarious nature which previously characterized the community. Joint enterprise has been largely replaced by individual endeavor, an increase in household-centered life contributing to a fragmentation of former community units into constituent family units. It was precisely that former community network which had supported nicknaming by allowing for the coinage of nicknames in group gatherings and, equally importantly, by fostering "the role that groups played in the diffusion of names throughout the community" (Barrett 103). The decline in community networking concomitant with modernization has led to a decrease in both the numbers of nicknames created and the numbers of new nicknames which succeed in becoming established. This demonstrates the manner by which an analysis of changing nicknaming practices can afford insight into the processes of social change.

We may turn our attention for a moment from the realm of personal nicknames to "official" or "public" nicknames, those recorded nicknames by which individuals were (and are) known to the public - such as "Babe" Ruth. Skipper has pioneered the study of such names, in which processes of social change emerge as crucial ingredients in accounting for shifting patterns in public nicknaming. His 1984 and 1985 studies of the nicknames of baseball players and twentieth-century deviants illustrate his thesis.

Skipper notes that baseball in America grew up during the folk-hero era, and baseball players - often immigrants and people of low educational background - frequently achieved the status of folk heroes. They exemplified, to the public "how 'folk people' could receive recognition, financial success, and general social mobility no matter how humble their origins" ("Sociological Significance" 31). A high frequency of nicknames for baseball players thus reflected the public's ability to feel close to those players, an almost mythical quality fostered by baseball's seeming isolation from the world of business. 
Skipper notes an enormous decline in the frequency of such nicknames in the decades following World War II. This he attributes to the decline of the folk-hero myth as franchises and unions invaded the world of baseball and boycotts and strikes by players tarnished the mythical ethos. Free agency by players began in 1974, and with the negotiation of multi-million dollar contracts, "the image of the baseball player in the public's mind changed from folk hero to shrewd entrepreneur" (33). A drastic reduction in nicknaming reflected the public's increasing inability to feel identity with the baseball players, a decline concomitant with increasing disbelief in the legends and myths of folk heroes in general. His study of nicknames among black baseball players ("Nicknames, Folk Heroes, and Assimilation") similarly supports this conclusion, while additionally illustrating some of the mechanics of assimilation by which those players could become a part of the larger sports culture.

Similar sociological mechanics are evident in Skipper's 1985 analysis of nicknames among twentieth-century deviants. Especially insightful is the sharp decline in nicknaming of those categories of deviants who might be called innovators - of which the gangster-racketeer-bootlegger was the archetype. During Prohibition, he states, "Gangsters and racketeers who supplied ... illegal booze were treated as heroes," while during the Depression, many of "those who robbed the haves in a have not era" were catapulted into hero status ("Nicknames of Notorious Deviants" 110). With the passing of Prohibition and the Depression, and an increasing social and welfare legislation designed to take care of those who could not take care of themselves, the belief in both this type of folk hero and the rags-to-riches complex began to erode. Notes Skipper: "The death of the belief in the innovator as folk hero was in large part responsible for the decline in the use of public nicknames for deviants" (111).

Skipper ${ }^{1}$ observes roughly similar patterns in his analyses of nicknaming patterns for jazz musicians, blues singers, and football players, and in the numbers of placenames used as nicknames for major league baseball players, where he notes an unusually large proportion of place nicknames derived from the South, probably reflecting the development of a sense of Southern solidarity and regionalism). Declining frequencies of public nicknames are indicative of that general shift in American society from a Gemeinschaft to a Gesellschaft orientation-from a solidarity rooted in tradition and personal relationships to an orientation rooted in individualism and impersonality. In thus marking the transition from folk-rural to mass-urban society, nicknaming patterns emerge as 
indicators of sociological change on a strategic level.

To the studies thus far mentioned, we can add yet other references of interest. F. G. Bailey's book, for example, contains a number of references to nicknaming in Europe; William Bright touches upon nicknames among the Karok Indians of California; M. B. Nsimbi notes the use of nicknames among the Baganda of Uganda; while W. H. Goodenough mentions their use among the Truk (Micronesia) and Lakalai (northeast of New Guinea). Thomas V. Busse briefly examines the usage of nicknames in an American high school, noting that they were more frequent among boys than girls, were most commonly used by segments of the peer group, and were usually discarded by adulthood. Skipper ("Feminine Nicknames") enumerates the feminine nicknames which have been used by major league ball players (again noting a decreasing use over time concomitant with the decline of the folk-hero syndrome), and, with Paul L. Leslie, gives an analysis of nicknaming among female blues singers, in which he found that females received a lower percentage of nicknames than did their male counterparts, due in part to gender role expectations which gave them diminished access to occupational status and success. Both Edwin D. Lawson and Emily S. Dexter support a correlation between nicknames and self-concept and popularity; Fine ("Small Groups") briefly examines the role of nicknames in the idioculture of little league baseball teams; while João de Pina-Cabras reinterprets the previously mentioned investigations of nicknaming by Breen and Gilmore in terms of the differential experiencing of community. Barbara A. Buchanan and James L. Bruning report on the connotative meanings of nicknames, suggesting that such names can lead to expectations which affect our perceptions.

The foregoing review, though not exhaustive, well represents the scope of available English-language scholarship as it pertains directly to nicknaming; and in choosing to isolate and highlight but a few major themes from the aforementioned works, I have surely not done justice to the richly suggestive onomastic smorgasbord with which we find ourselves presented. Nevertheless, we begin to perceive the many faces of nicknames: we are left with the suggestion that they are more common among men than women, and more so among children than adults; we see their declining public usage; and we see them in many roles - as terms of reference and address, as tools of individuation, as identifying and classificatory devices; we see them functioning to maintain boundaries, as psychodynamic agents of ego-identity and oral agression, as instru- 
ments of social solidarity or social control. We view them from perspectives variously structural, functional, psychodynamic, and socio-historical. Like the proverbial blind men examining the elephant, each study provides yet another piece to a fascinating and complex puzzle. Taken as a whole, we begin to sense the true dimensions of nicknaming.

To conclude this review, I would like to present a few brief observations from my perspective as a newcomer to onomastics. To begin with, virtually all studies of nicknames start with an assessment of categories or "types" of nicknames, for, as Skipper and Leslie note, "the first step in any systematic study of a set of names is to develop a scheme of classification" ("Nicknames and Blues Singers. Part II" 31). We may, for example, apply an initial level of definition to our domain by accepting or excluding short names as instances of nicknaming. Morgan et al. note (16) that "a nickname is an eke-name, derived from the Old English ecan, meaning to 'add to or augment.' In practical terms this means that simple abbreviations of officially given names ... will not count as nicknames ...." Skipper concurs, as for example in his studies of coal miners and jazz musicians, while Mook, investigating nicknames among the Amish, admits short names to be a form of nickname, as I do in my study of railroaders' nicknames and as Harold B. Allen does in his classification of Egyptian Arabic nicknames. Other divisions may be imposed upon that data, such as the dichotomy between "internal formulation" (a function of one's given name) and "external formulation" (a function of an extralinguistic referent, such as a physical characteristic or critical event) (Morgan et al. 9). Most researchers then proceed by grouping the nicknames: those based on the given name, on physical or personality characteristics, on habits, on geography or place of origin, on lineage, or on events, occupation, traditions, cultural stereotypes, or other sorts of associations.

The issue here is whether or not we are actually constructing "psychologically real" models. What does a typology framed in terms of "internal" versus "external formulation" actually mean if the children who use such nicknames do not think in these terms? Or can we exclude short names from a study of nicknaming practices in a particular group without first asking whether the members of that group consider them to be examples of nicknames or not?

The importance of obtaining a "psychologically real" model is that such a model does more than merely order the data under investigation; 
it provides a description of semantic characteristics which is culturally revealing. The intent is to provide a presentation "of observed and elicited events according to the principles of classification of the people [one is] studying. To order ethnographic observations solely according to an investigator's preconceived categories obscures the real content of culture: how people organize their experience conceptually ..." (Frake 38). The point is simply that the assumptions which underlie a researchers' classificatory scheme must be clearly addressed; to proceed without such awareness may mean that the resulting study tells more about what the nicknames under investigation mean to the researcher than to the communities which actually utilize them! For this reason, the study of nicknaming practices must proceed in the direction of greater collaboration and engagement between researchers and subjects.

Secondly, is it possible as Michael Jackson suggests (17) that our upbringing as researchers "commits us to classification, and the conventional forms of our discourse trap us in dualisms and dichotomies"? Perhaps an awareness of the conceptual chains which encumber us can increase our sensitivity to other sorts of characteristics which nicknames may possess. As an example, in studying nicknaming among the Kamsá of Colombia, McDowell notes that such names exhibit esthetic qualities which are conducive to their assimilation into the oral tradition - such as acoustic texturing with patterned phonological components, metaphor, brevity, and stressing of syllables for metric effect. I have observed a formulaic pattern to railroaders' recitation of nicknames, perhaps indicative of a deeply embedded metacommunicative frame which suports those names' ability to function in the manner that they do. We thus see nicknaming in terms of performance and verbal artistry-only hints, to be sure, of the fascinating realms which yet await our serious investigation.

Thirdly, the lack of available data constitutes a serious hindrance, as "the nicknames of ordinary people are usually not documented and preserved" (Skipper and Leslie, "Nicknames and Blues Singers. Part I" 39). As one example, nickname usage in cities has been virtually neglected, perhaps because of the general conception that cities lack the structural features or types of social relationships which endow nicknames with functional utility. This leads to such conventional, though perhaps questionable, assertions as "[nicknames] have always flourished best in rural communities where everyone knows his neighbors more intimately than is possible in urban centers" (Fucilla, "Spanish" 139). 
The crucial point is that nicknaming is not a function of group size or demography per se, but of community-and "community" can be defined in far more than merely spatial terms. Jack Glazier, for example, in examining an eroding Jewish settlement in Indianapolis, notes that "the generation coming of age in the neighborhood, yet choosing to leave it in their effort to achieve economic mobility, can now expressively recreate that community and their youthful place therein through its narratives and nicknames" (83). I have documented nicknaming among railroaders in a steam-era city, observing that the backdrop of common knowledge and assumptions shared by those workers provided the "moral unity" which allowed such naming to occur. Thus we see community defined in terms of "an idea or a memory disembodied from its original physical representation" (Glazier 84), or in terms of those individuals who share a common work arena. Nicknaming among occupational groups (steelworkers, etc.) and within urban enclaves would seem to be one exceptionally fertile field, and no doubt a wealth of resources remains to be uncovered. Those onomasts who supplement their perusal of written records with a serious commitment to fieldwork will find themselves richly rewarded.

Regarding the status of onomastics as it relates to nicknaming, much more could be said, though brevity demands that these comments be brought to a close. In summation, we can state that while interest in nicknaming has increased substantially since the 1960s, serious scholarly investigation is yet in its infancy. In wending our way toward a general typology of nicknaming practices, we have sketched out the broad outlines and have begun to elucidate the principal features of that fascinating namescape. We have arrived at a threshold which demands their definition in terms of process and complex contextualized behavior. Our continuing endeavor will be guided by an awareness that nicknames are part of a complex human ecology, that they can arise from a large variety of naming strategies, that they simultaneously participate in a whole range of social and psychological functions, and that they bear attributes - perhaps many of them - which yet remain to be investigated or even discovered. A commitment to fieldwork and a willingness to allow our understanding of nicknaming to arise from out of our interaction with those individuals and communities we "study"-these are the qualities which will carry us into the future.

Finally, we must not allow the language of scientific discourse to obscure those human dimensions of life which ultimately we seek to 
understand. Perhaps we must bear in mind that mathematical or mechanical models or social theories per se do not represent the essence of lived experience. It is in casting the reader into the realm of the subject in such a way as to make him a part of the world we are studying-in traveling to that domain and narrowing the epistemological gap between "self" and "other" - that the onomastics of personal nicknaming will have arrived at the leading frontiers of social science. Nicknames are a sort of human mirror in which we see reflected the intersection of individual lives and community experience; to explore their myriad dimensions without losing sight of that humanity is the challenge we face.

Altoona, Pennsylvania

\section{Note}

1. See "Nicknames, Folk Heroes and Jazz Musicians"; (with Paul L. Leslie) "Nicknames and Blues Singers" (Parts I and II); "Public Nicknames"; and "Placenames."

\section{Works Cited}

Allen, Harold B. "Nicknaming in Egyptian Arabic." Names 4 (1956): $75-82$.

Anderson, Myrdene. "Proper Names, Naming, and Labeling in Saami." Anthropological Linguistics 26 (1984): 186-201.

Antoun, Richard T. "On the Significance of Names in an Arab Village." Ethnology 7 (1968): 158-70.

Bailey, F. G., ed. Gifts and Poisons. Oxford: Basil Blackwell, 1971.

Barrett, Richard A. "Village Modernization and Changing Nicknaming Practices in Northern Spain." Journal of Anthropological Research 34 (1978): 92-108.

Brandes, Stanley H. "Social Structure and Interpersonal Relations in Navanogal, Spain." American Anthropologist 75 (1973): 750-65.

. "The Structural and Demographic Implications of Nicknames in Navanogal, Spain." American Ethnologist 2 (1975): 139-48.

Breen, Richard. "Naming Practices in Western Ireland." Man 17 (1982): 701-13.

Bright, William. "Karok Names." Names 31 (1983): 172-79.

Buchanan, Barbara A., and James L. Bruning. "Connotative Meanings of First Names and Nicknames in Three Dimensions." Journal of Social Psychology 85 (1971): 143-44. 
Busse, Thomas V. "Nickname Usage in an American High School." Names 31 (1983): 300-06.

Cleveland, Ray L. "A Comment on the 'Floral Nicknames' in the Geniza Documents." Journal of the American Oriental Society 93 (1973): 200-02.

Cohen, Eugene N. "Nicknames, Social Boundaries, and Community in an Italian Village." International Journal of Contemporary Sociology 14 (1977): 102-13.

Collier, George A., and Victoria R. Bricker. "Nicknames and Social Structure in Zinacantan." American Anthropologist 72 (1970): 289302.

Dexter, Emily S. “Three Items Related to Personality: Popularity, Nicknames, and Homesickness." Journal of Social Psychology 30 (1949): 155-58.

Dorian, Nancy C. "A Substitute Name System in the Scottish Highlands." American Anthropologist 72 (1970): 303-19.

Eberhard, Wolfram. "A Note on Chinese Nicknames." In W. Eberhard, ed., Studies in Chinese Folklore and Related Essays. Indiana University Folklore Institute Monograph Series 23 . Bloomington: Indiana UP, 1970.

Fine, Gary Alan. "Small Groups and Culture Creation: The Idioculture of Little League Baseball Teams." American Sociological Review 44 (1979): 733-45.

. A review of Nicknames: Their Origins and Social Consequences, by Morgan et al. Journal of American Folklore 95 (1982): 92-93.

Foster, George M. "Speech Forms and Perception of Social Distance in a Spanish-Speaking Mexican Village." Southwestern Journal of Anthropology 20 (1964): 107-22.

Fox, J. R. "Structure of Personal Names on Tory Island." Man 63 (1963): $153-55$.

Frake, Charles O. "The Ethnographic Study of Cognitive Systems." In Stephen Tyler (ed.), Cognitive Anthropology. New York: Holt, Rinehart and Winston, 1969.

Fucilla, Joseph G. "Portuguese Nicknames as Surnames." Names 27 (1979): 73-105.

. "Spanish Nicknames as Surnames." Names 26 (1978): 139-76.

Gilmore, David D. "Some Notes on Community Nicknaming in Spain." Man 17 (1982): 686-700.

Glazier, Jack. "Nicknames and the Transformation of an American Jewish Community: Notes on the Anthropology of Emotion in the Urban Midwest." Ethnology 26 (1987): 73-85.

Goitein, S. D. "Nicknames as Family Names." Journal of the American Oriental Society 90 (1970): 517-24. 
Goodenough, W. H. "Personal Names and Modes of Address in Two Oceanic Societies." In M. Spiro ed., Context and Meaning in Cultural Anthropology. New York: 1979.

Hale, Christopher S. "Modern Icelandic Personal Bynames." Scandinavian Studies 53 (1981): 115-46.

Harre, Rom. "What's in a Nickname?" Psychology Today Jan. 1980: 78-84.

Harris, Ron. "What's in a Nickname?" Ebony July 1979: 76-83.

Holland, Theodore J., Jr. "Aspects of Community in Steam-Era Altoona: Working Papers." Unpublished manuscript, 1989.

- "Nicknaming Practices in a Steam-Era Railroad Town," Thesis. U of Oklahoma, 1987.

Iszaevich, Abraham. "Household Renom: The Traditional Naming System in Catalonia." Ethnology 19 (1980): 315-25.

Jackson, Bruce. "Prison Nicknames." Western Folklore 26 (1967): 48-54.

Jackson, Michael. Paths Toward a Clearing. Indianapolis: Indiana UP, 1989.

James, Allison. "The Game of the Name: Nicknames in the Child's World." New Society 14 (1979): 632-34.

Jönsjö, Jan. Studies on Middle English Nicknames. Lund: C.W.K. Gleerup, 1979.

Kehl, Frank. "Chinese Nicknaming Behavior: A Sociolinguistic Pilot Study." Journal of Oriental Studies 9 (1971): 149-72.

Lawson, E. D. "Men's First Names, Nicknames, and Short Names: A Semantic Differential Analysis." Names 21 (1973): 22-27.

Manning, Frank C. "Nicknames and Number Plates in the British West Indies." Journal of American Folklore 87 (1974): 123-32.

Maurer, David W., and Allan W. Futrell. "Criminal Monickers." American Speech 57 (1982): 243-55.

McDowell. John H. "Toward a Semiotics of Nicknaming: The Kamsá Example." Journal of American Folklore 94 (1981): 1-18.

McGeachy, John A. III. "Student Nicknames for College Faculty." Western Folklore 37 (1978): 281-96.

Mook, Maurice A. "Nicknames Among the Amish." Names 15 (1967): 111-18.

Morgan, Jane, Christopher O'Neill, and Rom Harré. Nicknames: Their Origins and Social Consequences. London: Routledge \& Kegan Paul, 1979.

Nsimbi, M. B. "Baganda Traditional Personal Names." Uganda Journal 14 (1950): 204-214.

Opie, Iona, and Peter Opie. Lore and Language of Schoolchildren. Oxford: Oxford UP, 1959. 
Pina-Cabras, João de. "Nicknames and the Experience of Community." Man 19 (1984): 148-50.

Pitt-Rivers, Julian A. The People of the Sierra. Chicago: Phoenix, 1961.

Price, Richard, and Sally Price. "Saramaka Onomastics: An AfroAmerican Naming System." Ethnology 11 (1972): 341-67.

Seltén, Bo. Early East-Anglian Nicknames. Lund: C.W.K. Gleerup, 1975. Skipper, James K., Jr. "Feminine Nicknames: 'Oh You Kid,' From Tilly to Minnie to Sis." Baseball Research Journal 11 (1982): 92-96.

. "Nicknames, Coal Miners and Group Solidarity." Names 34 (1986): 134-45.

. "Nicknames, Folk Heroes, and Assimilation: Black League Baseball Players, 1884-1950." Journal of Sport Behavior 8 (1985): 100-14.

. "Nicknames, Folk Heroes and Jazz Musicians." Popular Music and Society 10 (1986): 51-62.

. "Nicknames of Notorious American Twentieth-Century Deviants: The Decline of the Folk Hero Syndrome." Deviant Behavior 6 (1985): 99-114.

."Placenames Used as Nicknames: A Study of Major League Baseball Players." Names 38 (1990): 1-20.

- "Public Nicknames of Famous Football Players and Coaches: A Socio-Historical Analysis and Comparison." Sociological Spectrum 9 (1989): 103-23.

. "The Sociological Significance of Nicknames: The Case of Baseball Players." Journal of Sport Behavior 7 (1984): 28-38.

Skipper, James K., Jr., and Paul Leslie. "Nicknames and Blues Singers. Part I:Frequency of Use 1890-1977." Popular Music and Society 12.1 (1988):37-48.

."Nicknames and Blues Singers 1890-1977. Part II: Classification and Analysis." Popular Music and Society 13.3 (1989): 29-43.

. "Women, Nicknames, and Blues Singers." Names 36 (1988): 193202.

Tucker, Nicholas. "Sticks and Stones...." New Society 21 (1979): 728-29.

Van Buren, Henry. "The American Way with Names." In R. Breslin, ed., Culture Learning: Concepts, Applications and Research. Honolulu: University of Hawaii Press, 1974. 67-86.

Wakefield, Walter L. "Pseudonyms and Nicknames in Inquisitorial Documents of the Middle Ages in Southern France." Names 27 (1979): 188-97.

Watson, Rubie S. "The Named and the Nameless: Gender and Person in Chinese Society." American Ethnologist 13 (1986): 619-31.

Yassin, M. Aziz F. "Personal Names of Address in Kuwaiti Arabic." Anthropological Linguistics 20 (1978): 53-63. 